\title{
Spinal Cholinergic Neurons and the Expression of Morphine Withdrawal Symptoms in the Rat
}

\author{
Dennis C. Marshall 1,a and Jerry J. Buccafuscot,2 \\ 'Department of Pharmacology and Toxicology and Department of Psychiatry, Medical College of Georgia, Augusta, \\ Georgia 30912 and ${ }^{2}$ Veterans Administration Medical Center, Augusta, Georgia 30901
}

\begin{abstract}
Behavioral and autonomic signs of the morphine withdrawal syndrome were measured in dependent rats injected with the opiate antagonist naloxone. The purpose of this study was to determine whether spinal cholinergic pathways play a role in the expression of spinally mediated withdrawal symptoms. Intrathecal (i.t.) administration of $1 \mu \mathrm{g}$ carbachol or $5 \mu \mathrm{g}$ neostigmine resulted in increases in mean anterial pressure (MAP) of 32 and $45 \mathrm{~mm} \mathrm{Hg}$, respectively, in conscious, freely moving rats. The pressor response to carbachol began almost immediately after injection, but that to neostigmine was delayed in onset. Both responses were completely abolished following i.v. injection of $2 \mathrm{mg} / \mathrm{kg}$ atropine. However, in spinal-transected (C-1), ventilated rats, i.t. injection of carbachol or neostigmine resulted in only small, transient increases in MAP. Intraarterial (i.a.) injection of $0.5 \mathrm{mg} / \mathrm{kg}$ naloxone to morphine-dependent rats resulted in an immediate increase in MAP (to $33 \mathrm{~mm} \mathrm{Hg}$ ) that lasted at least $1 \mathrm{hr}$. This was accompanied by classical behavioral signs of withdrawal. Pretreatment of dependent rats with i.t. injection of atropine or hemicholinium-3 (HC-3) significantly reduced the pressor and several behavioral responses elicited by naloxone. In contrast, when morphine-dependent, spinal-transected rats were pretreated with i.t. injection of cholinergic antagonists, i.a. injection of naloxone resulted in an enhanced MAP response. Finally, in intact dependent rats, i.t. injection of naloxone $(6 \mu \mathrm{g})$ produced a $14 \mathrm{~mm} \mathrm{Hg}$ increase in MAP that was significantly augmented $(21 \mathrm{~mm}$ Hg) following i.t. pretreatment with $\mathrm{HC}-3$. These results may be explained by the presence of a descending spinal cholinergic pathway that facilitates the autonomic component of morphine withdrawal and an intrinsic spinal cholinergic pathway that is inhibitory to the expression of withdrawal.
\end{abstract}

In drug-dependent rats, there is a significant pressor response associated with morphine withdrawal following systemic injection of the narcotic antagonist naloxone. Behavioral and autonomic signs of withdrawal can be elicited following the intraarterial (i.a.) injection (Buccafusco, 1983) of naloxone, as well as by injection of naloxone into localized areas of the CNS. For example, injection of naloxone into the lateral or fourth cerebral

\footnotetext{
Received Feb. 10, 1986; revised Aug. 29, 1986; accepted Sept. 13, 1986.

This work was supported by the Veterans Administration.

Correspondence should be addressed to Dr. Jerry J. Buccafusco at the above address.

'Present address: Pfizer International Inc., 235 East 42nd St., New York, NY 10017.

Copyright (C) 1987 Society for Neuroscience $0270-6474 / 87 / 030621-08 \$ 02.00 / 0$
}

ventricles elicits a pattern of responses similar to, but with a slightly different temporal profile from, i.a. injections. In addition, marked behavioral and autonomic withdrawal symptoms are also observed following intrathecal (i.t.) injection at the level of the spinal sympathetic outflow (Marshall and Buccafusco, 1985b). The importance of the spinal cord in mediating autonomic symptoms of withdrawal is underscored by the observation that 2 consecutive withdrawal pressor responses of equal magnitude could be elicited when the first injection of naloxone was administered into the lateral ventricle and the second into the intrathecal space. Conversely, once the spinal cord was withdrawn, a second withdrawal response could not be elicited by injection of naloxone via any other route of administration (Marshall and Buccafusco, 1985b).

The spinal cord itself is capable of mediating a withdrawal response, i.e., a marked pressor response (up to $80 \mathrm{~mm} \mathrm{Hg}$ ) was observed in spinal transected (C-1), morphine-dependent rats (but not in spinal-transected, nondependent controls) following i.a. injection of naloxone (Buccafusco and Marshall, 1985). This spinally mediated withdrawal response was abolished following selective surgical lesions of the dorsal roots from T-3 to L-4. Thus, continuous peripheral afferent input as well as local opiate receptors are required for the autonomic expression of spinal narcotic withdrawal. Finally, in addition to naloxone-precipitated withdrawal, morphine-dependent, C-1-transected rats demonstrated spontaneous withdrawal of the spinal cord (Marshall and Buccafusco, 1985c). These results clearly indicate a role for both supraspinal and spinal opiate receptors in the autonomic response to morphine withdrawal and are consistent with similar findings from other laboratories (Martin and Eades, 1964; Martin et al., 1976; Delander and Takemori, 1983).

Earlier experiments from our laboratory (Marshall and Buccafusco, 1983) have indicated that the pressor response observed in morphine-dependent rats following i.a. injection of naloxone was significantly reduced in rats pretreated with an intracerebroventricular injection of the ACh-depleting drug hemicholinium-3 (HC-3). This experiment was predicated on the fact that pharmacologic stimulation of central cholinergic receptors increases sympathetic activity, resulting in a hypertensive response. Hypertension following central cholinergic stimulation has been observed in a number of vertebrate species, including man (for review, Brezenoff and Giuliano, 1982). It is not yet clear if such a cholinergic pathway exists within the rat spinal cord.

The purposes of the present study were (1) to identify the existence of spinal cholinergic receptors that mediate a hypertensive response in the intact and spinal transected rat, and (2) 
to determine whether blockade of spinal cholinergic receptors or depletion of spinal cord ACh levels alters the pressor response to naloxone in morphine-dependent rats.

\section{Materials and Methods}

Animals. Male Wistar rats (250-380 gm) obtained from Harlan Industries, Inc. (Indianapolis, IN) were housed in an environmentally controlled room on a $12 \mathrm{hr}$ light-12 hr dark cycle and supplied with fond (Wayne Rodent Bloks) and tap water ad libitum. The same lighting cycle and conditions were maintained after surgery.

Intrathecal surgery. Rats were anesthetized with methohexital (65 $\dot{\mathrm{mg}} / \mathrm{kg}$, i.p.) and placed in a small animal stereotaxic instrument. Chronic catheterization of the spinal subarachnoid space was performed according to a modified procedure described by Yaksh and Rudy (1976) by inserting a length of saline-filled polyethylene (PE) 10 tubing, $5.5 \mathrm{~cm}$ caudal to a midline nick in the altanto-occipital membrane, terminating in the T-7/T-8 segments of the spinal cord. The opposite end of the tubing was threaded through $2(1.0 \mathrm{~mm})$ burr holes in the skull, anchored in place by a loose overhand knot in the tubing and externalized at the top of the head. The same procedure of cannula implantation was employed in halothane-anesthetized animals just prior to spinal cord transection (see below). The rostral end of the cannula was plugged with a removable 30 gauge stylette and anchored to the skull with acrylic cement. Animals were allowed $5 \mathrm{~d}$ to recover prior to vascular surgery. Upon completion of the experiments, cannula placement was confirmed by dye injection and dorsal laminectomy. The attachment of the 12th rib to the T-12 vertebrate was used as a landmark for determining the precise placement of the i.t. cannulae.

Vascular surgery. Rats were anesthetized with methohexital, a midline abdominal incision was made, and the viscera were displaced laterally to expose the left iliac artery. A lenth of PE 50 tubing filled with heparinized ( 20 units $/ \mathrm{ml}$ ) saline was inserted so the tip of the catheter terminated in the base of the abdominal aorta, below the origin of the renal arteries. The opposite end of the tubing was plugged with a 23 gauge stylette and directed rostrally to emerge at the nape of the neck. Following surgery the animals were returned to their home plastic cages $(45 \times 25 \times 20 \mathrm{~cm})$, and the arterial cannula was passed through a stainless steel spring support connected to a watertight swivel cannula (Instech Laboratories, Fort Washington, PA) mounted $30 \mathrm{~cm}$ above the cage floor. In some animals a chronic indwelling intravenous (i.v.) catheter (PE-50) was implanted in the right jugular vein during the same surgical session. This catheter was also exteriorized at the nape of the neck. This method allowed the chronically catheterized animal unrestricted movement to all areas of the cage while a constant infusion $(0.33 \mathrm{ml} / \mathrm{hr})$ of heparinized $(20 \mathrm{units} / \mathrm{ml})$ saline maintained the patency of the arterial catheter. Each animal received a prophylactic intramuscular injection of penicillin $\mathrm{G}(60,000$ units). Animals were allowed to recover for $1 \mathrm{~d}$ prior to beginning the morphine infusion schedule.

Morphine infusion schedule. Rats were made physically dependent upon morphine according to a modified schedule (Fielding et al., 1978) for i.v. infusion. One day after vascular surgery, rats were infused with morphine sulfate through the arterial catheter at a rate of $0.33 \mathrm{ml} / \mathrm{hr}$ to deliver a total dose of $35 \mathrm{mg} / \mathrm{kg} / \mathrm{d}$. The animals were weighed on the day of vascular surgery and $5 \mathrm{gm}$ added to account for weight gain during the infusion schedule. For the next $4 \mathrm{~d}$, the concentration of morphine was adjusted each morning to deliver 50,75, 100 and 100 $\mathrm{mg} / \mathrm{kg} / \mathrm{d}$, respectively. Morphine sulfate was dissolved in sterile heparinized (20 units $/ \mathrm{ml}$ ) saline.

Precipitated withdrawal. Morphine withdrawal was precipitated by the administration of naloxone hydrochloride dissolved in sterile, heparinized ( 20 units $/ \mathrm{ml}$ ) saline. Naloxone was injected by the i.a. route as a rapid bolus $(0.25-0.38 \mathrm{ml})$ followed by $0.3 \mathrm{ml}$ saline. Subarachnoid i.t. injections $(10 \mu \mathrm{l})$ were delivered via a $50 \mu$ l Hamilton syringe over $15 \mathrm{sec}$, followed with a $10 \mu \mathrm{l}$ saline flush $(15 \mathrm{sec})$ to clear the i.t. catheter of drug.

Cardiovascular measurements. Blood pressure and heart rate were recorded through the arterial catheter connected to a Statham P23Db transducer coupled to a Beckman R 12 polygraph recorder. Heart rate was monitored by a Beckman 9857B cardiotachometer triggered from the arterial pressurc pulscs. Bascline blood pressurc and hcart rate were recorded for at least $15 \mathrm{~min}$ before and $60 \mathrm{~min}$ after naloxone injection. Arterial pressure was recorded continuously in all experiments with the mean arterial pressure (MAP) calculated as: $\mathrm{MAP}=$ diastolic + (systolic - diastolic)/3. The absolute increase in MAP over baseline was plotted versus time at each 5 min time interval following naloxone for $60 \mathrm{~min}$. Heart rate was recorded continuously in most experiments. However, changes in this parameter were not employed in our estimation of withdrawal intensity, since our earlier experiments indicated that heart rate changes were not a useful indicator of the degree of physical dependence (Marshall and Buccafusco, 1985a).

Behavioral measurements. The incidence of the following behavioral withdrawal signs were counted during the $60 \mathrm{~min}$ withdrawal period: Escape Attempts, ESC (vigorously attempting to leap or jump from cage); Withdrawal Body Shakes, WBS (or "wet-dog" shakes, brief episodes of rapid repetitive shaking of the entire body from side to side); Writhing, WRI (the presence of abdominal muscle stretchings observed as an arched back and abnormal posturing); and Kicking, KIC (brief, rapid, forceful kicking movements made by both hindlegs). Counted signs of WBS, ESC, KIC, and WRI were individually summed and data expressed as the means frequency of events during the $60 \mathrm{~min}$ period following naloxone. The presence or absence of the following checked signs were recorded during the $60 \mathrm{~min}$ withdrawal session: Lacrimation, LAC (the secretion of clear fluid from one or both eyes which pooled at the medial canthus); Defecation, DEF (normally formed stools); Diarrhea, DIA (loose or unformed stools); Teeth Chattering, TC (the audible, involuntary clicking of teeth); Chromodacryorrhea, CHR, which is the formation of red-brown, porphyrin-containing tears, produced by the harderian glands in response to stress and observed in the eyes and external nares (Harkness and Ridgway, 1980). Checked signs of LAC, CHR, DEF, DIA, and TC were recorded for $60 \mathrm{~min}$ after naloxone administration. The data are presented as the Number of animals exhibiting the signs/Total number examined.

Spinal cord transection. Surgical anesthesia was induced in morphinedependent rats by placing them in a jar containing halothane vapors. A tracheotomy was performed, and the rat was ventilated with a Harvard Rodent Respirator on line with a halothane vaporizer (Stanton Scientific Equipment Co., Glendale, CA) to maintain the level of anesthesia. Animals were ventilated with oxygen at a stroke volume of $1.8 \mathrm{ml}$ and a rate of 90 respirations $/ \mathrm{min}$. Blood pressure was measured directly from the arterial line, and the level of halothane anesthesia was titrated by monitoring changes in blood pressure. Rats were placed on a heating pad to maintain a colonic temperature of $37.0 \pm 0.1^{\circ} \mathrm{C}$, which was monitored via a thermistor probe (YSI-401/YSI-43TA) inserted $7.0 \mathrm{~cm}$ rectally.

Rats were oriented in a stereotaxic instrument, and a dorsal midline incision was made at the nape of the neck to expose the C-1 vertebra. The C-1 vertebra was removed with a bone rongeur to visualize the cord accurately, and the halothane was discontinued. A complete spinal cord transection was then made with a scalpel at the level of C-1. Animals were removed from the stereotaxic frame immediately following surgery.

Drugs. Naloxone hydrochloride was donated by Endo Laboratories (Garden City, NY). Morphine sulfate was purchased from Mallinkrodt (Paris, KY). Hemicholinium-3, atropine methyl bromide, neostigmine methyl sulfate, and carbamylcholine chloride were purchased from Sigma (St. Louis, MO). Dosages of all drugs are expressed in terms of the salt.

Statistical analysis. Values were presented as means \pm SEM. Comparison of proportions using a 1-way analysis of variance (ANOVA) was performed on arc sine transformed and nontransformed data or a $\log$-linear analysis. A Fischer's exact test was used to compare the independence of checked behavioral signs. Comparisons between the means of several populations were performed using ANOVA or an ANOVA for repeated measures and were considered significant at the $p<0.05$ level. The differences between means of 2 groups were estimated using Student's $t$ test for unpaired data.

\section{Results}

Cardiovascular and behavioral responses to intrathecal cholinergic agonists in nondependent and spinal-transected rats

Unanesthetized, nondependent, intact or spinal-transected rats received i.t. injections of the direct-acting cholinergic agonist, carbachol (1 $\mu \mathrm{g})$, or the indirect acting agonist, neostigmine (5 $\mu \mathrm{g}$ ), in order to evaluate the cardiovascular response elicited from spinal cholinergic stimulation. Intrathecal injection of either 

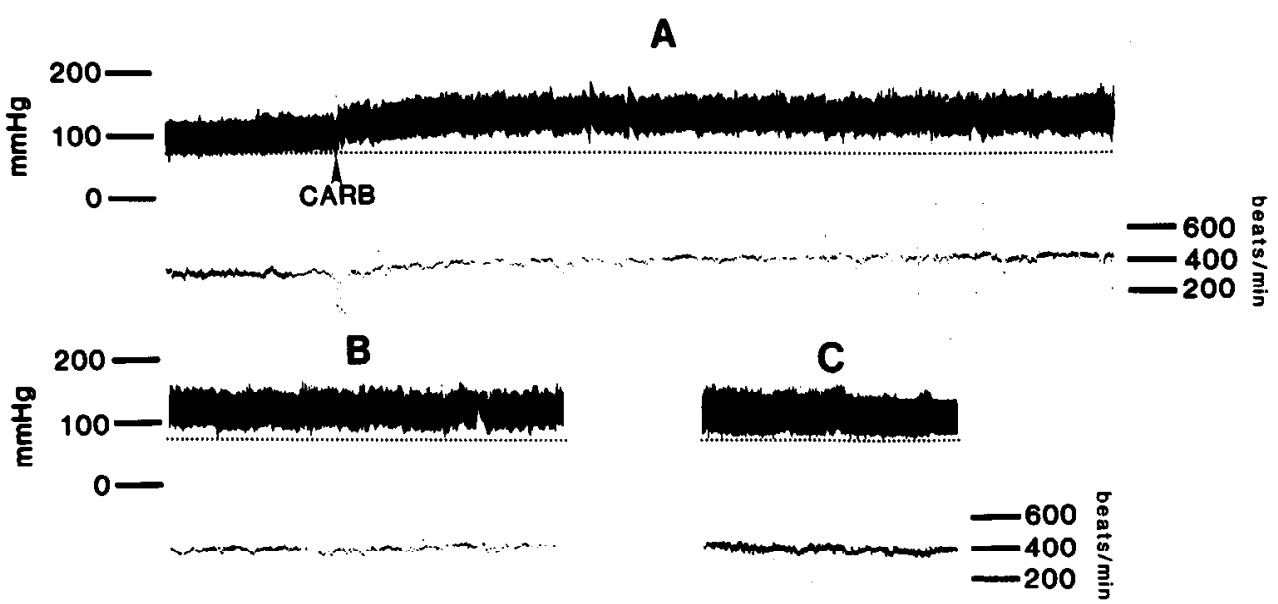

Figure 1. Actual representative blood pressure and heart rate tracing from a single nondependent rat following i.t. carbachol $(1 \mu \mathrm{g}$, arrowhead $) . A$, Blood pressure and heart rate tracing during the first $15 \mathrm{~min}$ of response. $B$, Blood pressure and heart rate response 15-25 min following carbachol. $C$, Blood pressure and heart rate response $50-60$ min following carbachol. Minutes 2540 not shown; dotted line represents baseline diastolic pressure. carbachol or neostigmine to previously quiet rats evoked overt behavioral changes of scratching, pecking motions, grooming, and ataxia. Thereafter, shivering, whole body tremors, and vocalizations occurred. Carbachol induced these behavioral responses within 2-5 min after injection, whereas neostigmineinduced responses appeared within 5-15 min. Neostigmine-induced responses appeared to be more intense and were of greater duration than those evoked by carbachol; however, no attempt was made to quantitate these behaviors.

Intrathecal injection of carbachol to intact animals evoked an immediate increase in MAP, which was maximal within 1 $\min (32 \pm 1 \mathrm{~mm} \mathrm{Hg})$ and remained elevated above baseline for $60 \mathrm{~min}$. Heart rate also increased by $58 \pm 14$ beats $/ \mathrm{min}$ but returned to baseline within $15 \mathrm{~min}$ of the injection. An actual blood pressure tracing is represented in Figure 1 and the mean blood pressure and heart rate values are presented in Table 1. The behavioral changes were not always temporally correlated with the cardiovascular changes, and, therefore, the activity per se was not responsible for the increase in MAP.

Intrathecal injection of neostigmine also evoked a pressor response in intact rats; however, the onset was delayed and the maximal increase in MAP ( $58 \pm 14 \mathrm{~mm} \mathrm{Hg}$ ) was not observed until between 3 and $4 \mathrm{~min}$ following the injection. The pressor response gradually declined with time (Table 2 ) but remained

\section{Table 1. Comparison of cardiovascular changes evoked by intrathecal injection of carbachol ${ }^{\mu}$ in intact, unanesthetized and spinal-transected (C-1) rats}

\begin{tabular}{lcccc} 
& & \multicolumn{2}{l}{ Mean arterial pressure $(\mathrm{mm} \mathrm{Hg})$} \\
\cline { 3 - 5 } & $N$ & $\begin{array}{l}\text { Pre- } \\
\text { injection } \\
\text { level }\end{array}$ & $\begin{array}{l}\text { Maximal } \\
\text { increase }\end{array}$ & $\begin{array}{l}\text { Increase } \\
15 \text { min } \\
\text { after } \\
\text { injection }\end{array}$ \\
\hline Preparation & 7 & $98 \pm 4$ & $32 \pm 1$ & $25 \pm 2$ \\
Intact, unanesthetized & 6 & $62 \pm 7^{d}$ & $17 \pm 4^{d}$ & $0^{c, d}$ \\
Spinal transected & & Heart rate (beats/min) & \\
\cline { 3 - 5 } Intact, unanesthetized & 7 & $322 \pm 8$ & $58 \pm 14$ & $0^{c}$ \\
Spinal transected & 6 & $268 \pm 5^{d}$ & $28 \pm 17$ & $0^{c}$
\end{tabular}

"Carbachol, $1 \mu \mathrm{g} / \mathrm{kg}$, was injected intrathecally through a previously implanted catheter.

${ }^{b}$ Cardiovascular changes always peaked within 5 min after injection.

c Cardiovascular changes returned to preinjection levels within 15 min after injection.

${ }^{d}$ Significantly different $(p<0.01)$ compared to means for intact animals. elevated over control levels after $60 \mathrm{~min}$. Notably, i.t. injection of neostigmine induced tachycardia ( $44 \pm 12$ beats $/ \mathrm{min})$ with profound cardiac arrhythmias, which were immediately abolished by atropine sulfate $(2 \mathrm{mg} / \mathrm{kg}$, i.v.). An actual blood pressure tracing (Fig. 2) illustrates these responses. Despite the fact that heart rate returned to baseline levels within 15 min after neostigmine, the arrhythmias persisted, often for more than $30 \mathrm{~min}$. These findings indicate the ability of intrathecally administered direct and indirect cholinergic agonists to evoke a hypertensive and tachycardic response in intact rats.

In all cases, i.t. administration of carbachol or neostigmine to spinal-transected rats evoked only transient cardiovascular responses, which were significantly lower than in intact animals. Carbachol evoked a pressor response of only $17 \pm 4 \mathrm{~mm} \mathrm{Hg}$ and a tachycardia of only $28 \pm 17$ beats $/ \mathrm{min}$, both of which returned to baseline within $15 \mathrm{~min}$ after injection (Table 1). Neostigmine induced only a $16 \pm 5 \mathrm{~mm} \mathrm{Hg}$ increase in MAP in transected animals and a $38+9$ beat $/ \mathrm{min}$ tachycardic response, both of which returned to baseline within $15 \mathrm{~min}$ after injection (Table 2). These results indicate that the pressor response evoked from intact rats by intrathecal administration of either direct- or indirect-acting cholinergic agonists is profoundly reduced by spinal cord transection.

Table 2. Comparison of cardiovascular changes evoked by intrathecal injection of neostigmine ${ }^{a}$ in intact, unanesthetized and spinal-transected (C-1) rats

\begin{tabular}{|c|c|c|c|c|}
\hline \multirow[b]{2}{*}{ Preparation } & \multirow[b]{2}{*}{$N$} & \multicolumn{3}{|c|}{ Mean arterial pressure $(\mathrm{mm} \mathrm{Hg})$} \\
\hline & & $\begin{array}{l}\text { Pre- } \\
\text { injection } \\
\text { level }\end{array}$ & $\begin{array}{l}\text { Maximal } \\
\text { increase }^{b}\end{array}$ & $\begin{array}{l}\text { Increase } \\
15 \mathrm{~min} \\
\text { after } \\
\text { injection }\end{array}$ \\
\hline Intact, unanesthetized & 6 & $95 \pm 4$ & $45 \pm 3$ & $37 \pm 6$ \\
\hline \multirow[t]{2}{*}{ Spinal transected } & 4 & $68 \pm 6^{d}$ & $16 \pm 5^{d}$ & $0^{c . d}$ \\
\hline & & \multicolumn{2}{|c|}{ Heart rate (beats/min) } & \\
\hline Intact, unanesthetized & 6 & $316 \pm 8$ & $44 \pm 12$ & $0^{c}$ \\
\hline Spinal transected & 4 & $253 \pm 10^{d}$ & $38 \pm 9$ & $0^{c}$ \\
\hline
\end{tabular}

${ }^{a}$ Neostigmine, $5 \mu \mathrm{g} / \mathrm{kg}$, was injected intrathecally through a previously implanted catheter.

${ }^{b}$ Cardiovascular changes always peaked within 5 min after injection.

c Cardiovascular changes returned to preinjection levels within 15 min after injection.

${ }^{d}$ Significantly different $(p<0.01)$. 
Figure 2. Actual representative blood pressure and heart rate tracing from a single nondependent rat following i.t. neostigmine ( $5 \mu \mathrm{g}$, arrowhead). $A$, Control blood pressure and heart rate recorded for $15 \mathrm{~min}$ prior to neostigmine; note normal appearance of blood pressure pulse where chart speed was increased. $B$, Elevation in blood pressure, and onset of cardiac arrhythmia (increased chart speed) following i.t. neostigmine (arrowhead). $C$, Intravenous atropine sulfate $(2 \mathrm{mg} / \mathrm{kg})$ administered immediately prior to start of tracing, which was $15 \mathrm{~min}$ after neostigmine; note return of blood pressure to preneostigmine level and the absence of cardiac arrhythmia.

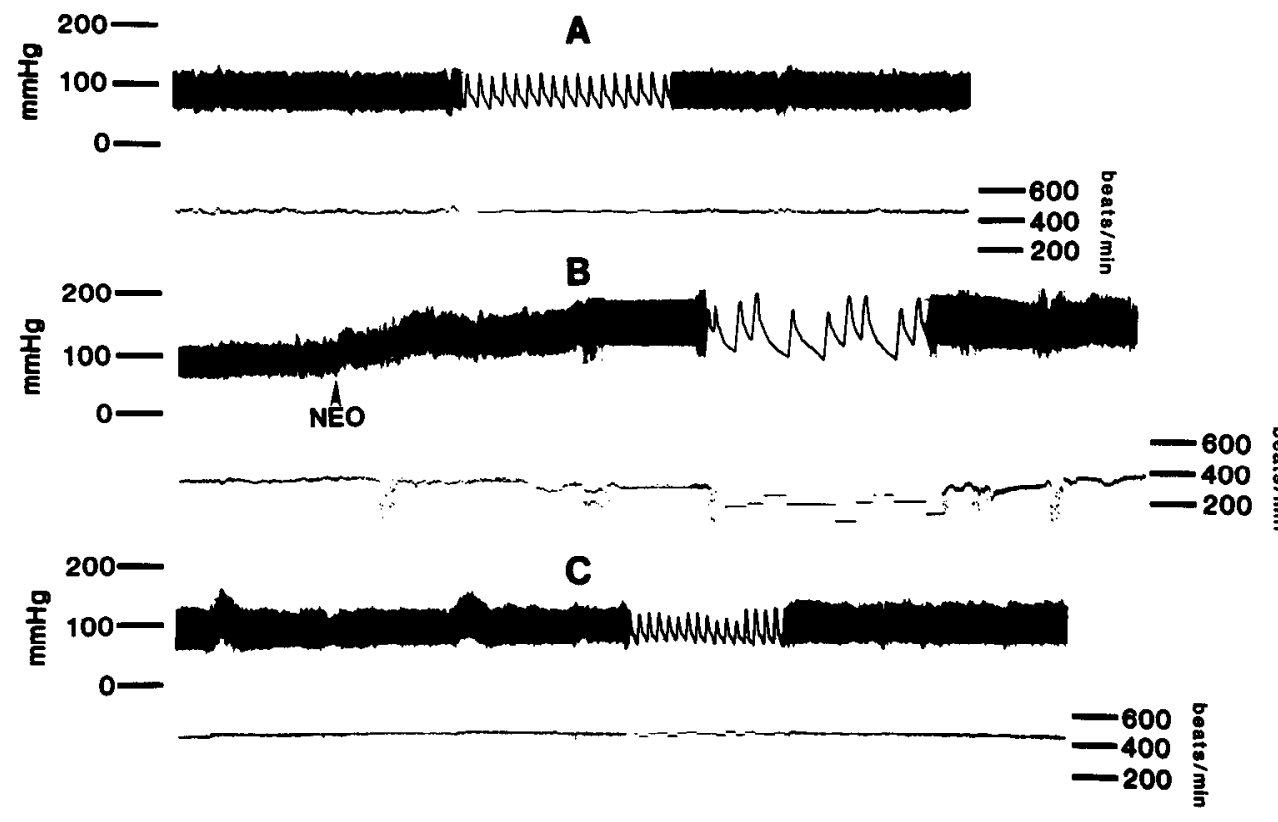

\section{Cardiovascular and behavioral changes during naloxone} precipitated withdrawal following intrathecal administration of cholinergic antagonists

Intact, morphine-dependent rats were pretreated with i.t. injections of saline, $\mathrm{HC}-3$, or atropine methylbromide prior to injection of naloxone $(0.5 \mathrm{mg} / \mathrm{kg}$, i.a.) in order to evaluate the contribution of spinal cholinergic neurons in mediating the withdrawal response. Saline-pretreated rats experienced the characteristic pressor response to naloxone, in which MAP peaked within $5 \mathrm{~min}(33 \pm 3 \mathrm{~mm} \mathrm{Hg})$ and gradually declined over the $60 \mathrm{~min}$ withdrawal period to $23 \pm 2 \mathrm{~mm} \mathrm{Hg}$. Intrathecal pretreatment with $\mathrm{HC}-3(25 \mu \mathrm{g})$ or atropinc $(20 \mu \mathrm{g})$ produced no observable cardiovascular or behavioral changes prior to injection of naloxone. However, following injection of naloxone, both HC-3 and atropine pretreatment significantly $(p<0.025)$ reduced the maximal increase in MAP $(14 \pm 3$ and $20 \pm 4 \mathrm{~mm}$ $\mathrm{Hg}$, respectively) and induced a more rapid decline in the pressor response toward baseline (Fig. 3). The between-group component of ANOVA for repeated measures revealed a highly sig- nificant difference $(F(2,13)=30.79 ; p<0.001)$ in the pressor responses. This finding substantiated the data in nondependent rats, which indicated that excitatory spinal cholinergic mechanisms mediate autonomic sympathetic activity.

Behavioral signs of naloxone-precipitated withdrawal were also affected by pretreatment with either HC-3 or atropine. HC-3 completely abolished WBS and blocked the occurrence of DIA. The frequency of ESC and the other checked signs of withdrawal were unaffected by pretreatment (Table 3). Atropine also effectively blocked WBS and DIA and significantly $(p<0.05)$ reduced the frequency of ESC over the 60 min withdrawal period (Table 3).

\section{Cardiovascular changes in spinal-transected rats during naloxone-precipitated withdrawal following intrathecal administration of cholinergic antagonists}

Morphine-dependent rats were allowed to stabilize for $30 \mathrm{~min}$ following spinal transection prior to injection of naloxone $(0.5$ $\mathrm{mg} / \mathrm{kg}$, i.a.). Intact animals were pretreated intrathecally prior to transection at 15,15 , and $30 \mathrm{~min}$, respectively, with either

Table 3. Comparison of behavioral responses to intraarterial injection of naloxone ${ }^{a}$ following intrathecal pretreatment with $\mathrm{HC}^{-3}$ or atropine ${ }^{c}$ in morphine-dependent rats

\begin{tabular}{|c|c|c|c|c|c|c|c|}
\hline \multirow{2}{*}{$\begin{array}{l}\text { Intrathecal } \\
\text { pretreatment }\end{array}$} & \multirow[b]{2}{*}{$N$} & \multicolumn{2}{|c|}{$\begin{array}{l}\text { Frequency of counted signs }{ }^{d} \\
\text { (observed } / 60 \mathrm{~min} \text { ) }\end{array}$} & \multicolumn{4}{|c|}{$\begin{array}{l}\text { Occurrence of checked signse } \\
\text { (animals exhibiting sign/ } \\
\text { total number animals) }\end{array}$} \\
\hline & & ESC & WBS & DEF & DIA & CHR & $\mathrm{TC}$ \\
\hline Saline & 6 & $8.8 \pm 1.9$ & $19.7 \pm 4.7$ & $6 / 6$ & $6 / 6$ & $5 / 6$ & $6 / 6$ \\
\hline Hemicholinium-3 & 5 & $8.0 \pm 1.9$ & or & $5 / 5$ & $0 / 5^{\prime}$ & $4 / 5$ & $5 / 5$ \\
\hline Atropine & 5 & $4.2 \pm 0.5^{f}$ & $0.6 \pm 0.2^{r}$ & $5 / 5$ & $0 / 5^{f}$ & $2 / 5$ & $5 / 5$ \\
\hline \multicolumn{8}{|c|}{${ }^{a}$ Unanesthetized morphine-dependent rats were administered an intraarterial injection of naloxone $(0.5 \mathrm{mg} / \mathrm{kg})$. } \\
\hline
\end{tabular}




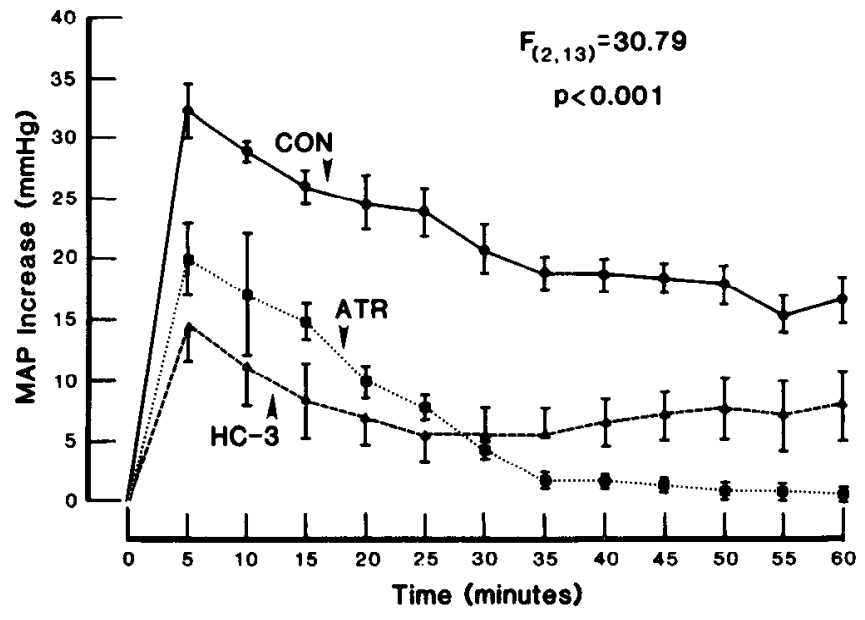

Figure 3. Increase in mean arterial pressure $(M A P)$ following intraarterial injection of naloxone $(0.5 \mathrm{mg} / \mathrm{kg})$ to unanesthetized, morphinedependent rats at time $0 . \operatorname{CON}(n=6)$, rats pretreated with i.t. saline (20 $\mu$ l over $30 \mathrm{sec}$ ) $30 \mathrm{~min}$ prior to naloxone; $A T R(n=5)$, rats pretreated with i.t. atropine methylbromide $(20 \mu \mathrm{g} / 10 \mu \mathrm{l}) 30 \mathrm{~min}$ prior to naloxone; $H C-3(n=5)$, rats pretreated with i.t. hemicholinium-3 $(25 \mu \mathrm{g} / 10 \mu \mathrm{l})$, 45 min prior to naloxone. $F, F$ ratio for between-group component of 1 way ANOVA for repeated measures. Vertical lines indicate SEM.

saline $(20 \mu \mathrm{l})$, atropine methylbromide $(20 \mu \mathrm{g})$, or HC-3 $(25 \mu \mathrm{g})$. The doses of the antagonists were employed based on our previous experience indicating maximal production of muscarinic receptor blockade or ACh depletion, respectively (Finberg et al., 1979; Buccafusco and Aronstam, 1981), following intraventricular injection. Naloxone evoked a characteristic pressor response from the saline-pretreated control group, which peaked at $76 \pm 3 \mathrm{~mm} \mathrm{Hg}$ and declined to $27 \pm 3 \mathrm{~mm} \mathrm{Hg}$ over the 60 min withdrawal session. Both HC-3 and atropine pretreatment resulted in a significantly augmented pressor response to naloxone. Naloxone evoked a maximal increase in MAP of $113 \pm 4$ $\mathrm{mm} \mathrm{Hg}(p<0.001)$ in the HC-3-pretreated group and an increase of $98 \pm 5 \mathrm{~mm} \mathrm{Hg}(p<0.001)$ in the atropine-pretreated animals. Thereafter, the pressor responses declined so that no significant differences existed between the treated and control groups. Although an initial augmented pressor response was apparent in the HC-3- and atropine-pretreated groups over the first $30 \mathrm{~min}[F(2,15)=10.78 ; p<0.001]$, ANOVA for repeated measures revealed no significant differences between groups when the entire $60 \mathrm{~min}$ time course curves were analyzed (Fig. 4).

\section{Cardiovascular and behavioral changes evoked by intrathecal naloxone following intrathecal pretreatment with $\mathrm{HC}-3$}

In an effort to test for the presence of a spinal cholinergic mechanism that inhibited the naloxone-induced pressor response, intact, morphine-dependent rats were administered i.t. saline $(20 \mu \mathrm{l})$ or $\mathrm{HC}-3(25 \mu \mathrm{g}) 45 \mathrm{~min}$ prior to i.t. naloxone $(6 \mu \mathrm{g})$. It was reasoned that localized spinal cord depletion of ACh by i.t. injection of HC-3 followed by i.t. injection of naloxone to the same region of the cord should evoke an augmented pressor response in intact animals. Neither saline nor HC-3 pretreatment produced any cardiovascular or behavioral changes. Following i.t. injection of naloxone, the saline control group exhibited an immediate increase in MAP of $14 \pm 1 \mathrm{~mm} \mathrm{Hg}$, which remained elevated at $15 \pm 2 \mathrm{~mm} \mathrm{Hg}$ after $60 \mathrm{~min}$. Pretreatment with i.t. HC-3 prior to i.t. naloxone resulted in an immediate pressor response of $18 \pm 2 \mathrm{~mm} \mathrm{Hg}$, which was significantly $(p<$

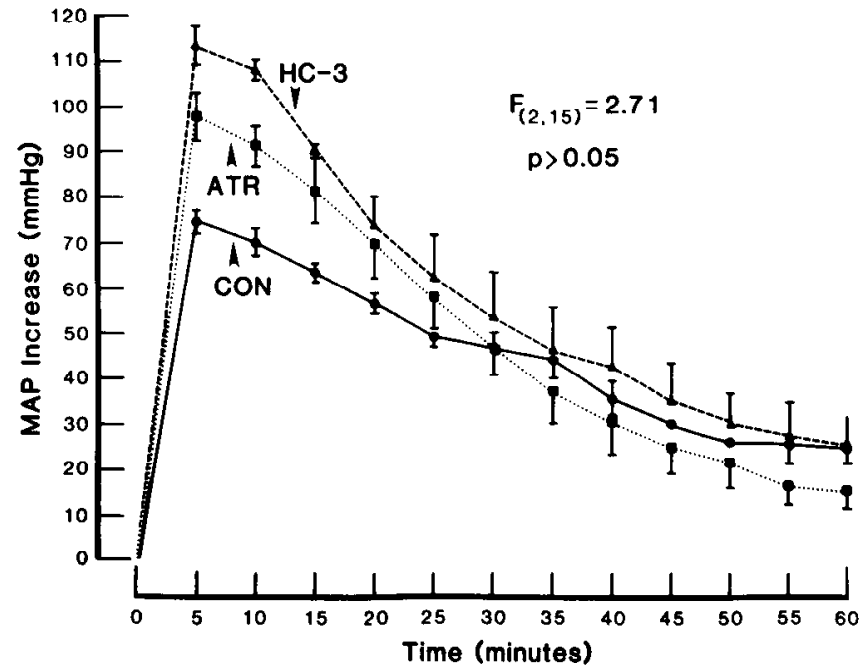

Figure 4. Increase in mean arterial pressure $(M A P)$ following intraarterial naloxone $(0.5 \mathrm{mg} / \mathrm{kg})$ to spinal-transected (C-1), morphine-dependent rats at time 0 . Unanesthetized, morphine-dependent rats were administered i.t. drug pretreatment, anesthetized with halothane, ventilated, transected at spinal level C-1, and allowed to stabilize for 30 min prior to naloxone. $C O N(n=7)$, rats pretreated with i.t. saline (20 $\mu l) 15$ min prior to spinal transection; $A T R(n=6)$, rats pretreated with i.t. atropine methylbromide $(20 \mu \mathrm{l} / 10 \mu \mathrm{l}) 15$ prior to transection; $H C-3$ $(n=5)$, rats pretreated with i.t. hemicholinium-3 $(25 \mu \mathrm{g} / 10 \mu \mathrm{l}) 30 \mathrm{~min}$ prior to transection. $F, F$ ratio for between-group component of 1 way ANOVA for repeated measures. Vertical lines indicate SEM.

$0.05)$ greater than the control group; the pressor response remained elevated at $21 \pm 1 \mathrm{~mm} \mathrm{Hg}$ after the $60 \mathrm{~min}$ withdrawal session. ANOVA for repeated measures also revealed a significant difference between the groups $[F(1,8)=10.75 ; p<0.025]$. The time course of the pressor responses is represented in Figure 5 .

Behavioral analysis also revealed significant differences in

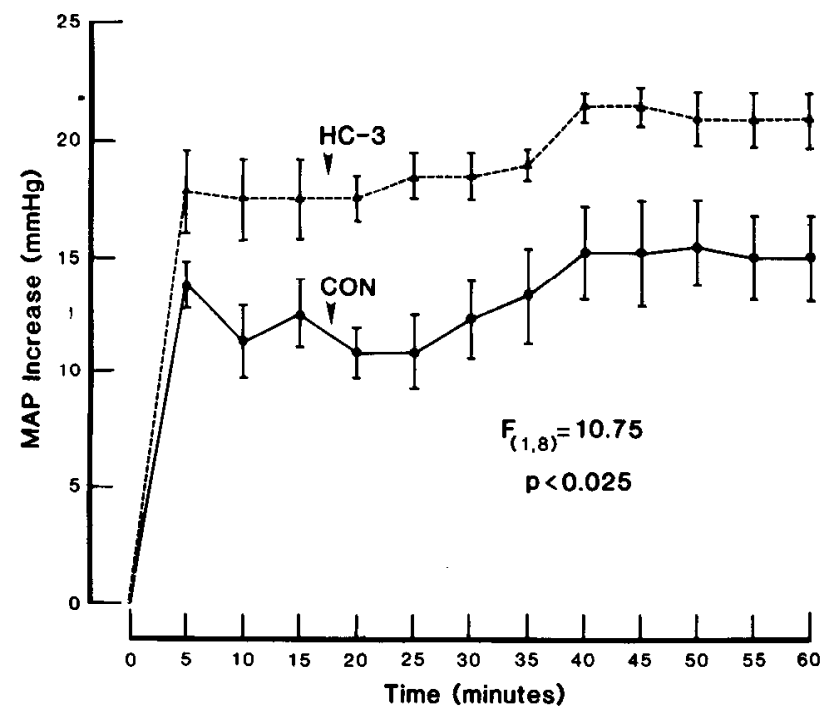

Figure 5. Increase in mean arterial pressure $(M A P)$ following i.t. naloxone $(6 \mu \mathrm{g} / 10 \mu \mathrm{l})$ injection to unanesthetized, morphine-dependent rats at time $0 . \operatorname{CON}(n=6)$, rats pretreated with i.t. saline $(20 \mu \mathrm{l}$ over $30 \mathrm{sec}) 45 \mathrm{~min}$ prior to naloxone; $H C-3(n=4)$, rats pretreated with i.t. hemicholinium-3 $(25 \mu \mathrm{g} / 10 \mu \mathrm{l}) 45 \mathrm{~min}$ prior to naloxone. $F, F$ ratio for between-group component of 1 way ANOVA for repeated measures. Vertical lines represent SEM. 
Table 4. Comparison of behavioral responses to intrathecal injection of naloxone ${ }^{a}$ following intrathecal pretreatment with $\mathrm{HC}^{-}{ }^{b}$ in morphine-dependent rats

\begin{tabular}{|c|c|c|c|c|c|c|c|}
\hline \multirow{2}{*}{$\begin{array}{l}\text { Intrathecal } \\
\text { pretreatment }\end{array}$} & \multirow[b]{2}{*}{$N$} & \multicolumn{2}{|c|}{$\begin{array}{l}\text { Frequency of counted signs } \\
\text { (observed } / 60 \mathrm{~min} \text { ) }\end{array}$} & \multicolumn{4}{|c|}{$\begin{array}{l}\text { Occurrence of checked signs }{ }^{d} \\
\text { (animals exhibiting sign } \\
\text { total number animals) }\end{array}$} \\
\hline & & $\mathrm{ESC}$ & WBS & $\overline{\mathrm{DEF}}$ & DIA & CHR & TC \\
\hline Saline & 6 & $16.7 \pm 1.5$ & $29.5 \pm 6.6$ & $5 / 6$ & $1 / 6$ & $5 / 6$ & $6 / 6$ \\
\hline Hemicholinium-3 & 4 & $12.2 \pm 2.2$ & $0^{e}$ & $3 / 4$ & $0 / 4$ & $0 / 4^{e}$ & $3 / 4$ \\
\hline
\end{tabular}

a Unanesthetized morphine-dependent rats were administered an intrathecal injection of naloxone $(6 \mu \mathrm{g} / 10 \mu \mathrm{l})$

${ }^{b}$ Hemicholinium $-3(25 \mu \mathrm{g} / 10 \mu \mathrm{l})$ was administered intrathecally $(\mathrm{T}-7$ to $\mathrm{T}-8) 45 \mathrm{~min}$ prior to naloxone.

c Comparison performed using Student's $t$ test.

¿ Comparison performed using Fischer's exact test.

- Significantly different from saline control mean, $p<0.05$.

ESC, cscape attempts; WBS, withdrawal body shakes; DEF, defecation; DIA, diarrhea; CHR, chromodacryorrhea; TC, teeth chatter.

characteristic signs of withdrawal. Pretreatment with HC-3 abolished the naloxone-precipitated occurrence of WBS, DIA, and CHR. A nonsignificant decrease in the frequency of ESC was also observed (Table 4).

\section{Discussion}

Cardiovascular and behavioral changes following intrathecal cholinergic agonists in nondependent rats

Several early studies (Schweitzer and Wright, 1937; Merlis and Lawson, 1939; Bulbring and Burns, 1941) demonstrated that cholinergic neurotransmission was involved in spinal reflex pathways. Later, the spinal cord work of Renshaw (1946) and Eccles et al. $(1954,1956)$ demonstrated, for the first time, a physiologically and anatomically defined CNS synapse operated by an identified neurotransmitter, $\mathrm{ACh}$. The role of $\mathrm{ACh}$ in spinal cord, as it relates to autonomic cardiovascular control, has not been determined. Autonomic preganglionic cell bodies, in the rat, stain intensely for $\mathrm{AChE}$, which is presumptive evidence that cholinergic neurotransmission occurs in this region (Navarathnam and Lewis, 1970). Evidence also exists to support the presence of cholinergic recurrent inhibition of sympathetic preganglionic neurons from within the thoracic spinal cord (Lebedev et al., 1980). However, microelectrophoretically applied cholinergic agonists do not appear to excite or inhibit sympathetic preganglionic neurons directly (Hongo and Ryall, 1966). Immunocytochemical detection of ChAT, which serves as stronger evidence for the presence of cholinergic neurons, has been localized within neurons located in both the dorsal horn (laminae II-III) and interomediolateral cell columns of the rat thoracic spinal cord (Houser et al., 1983). In brief, although cholinergic neurons are associated with spinal cord reflexes and exist in regions of the cord that modulate autonomic reflexes, no pharmacological studies have been conducted to elucidate the role of cholinergic neurons in spinal cord-mediated autonomic control.

In light of the fact that central cholinergic stimulation in the rat consistently evokes an augmentation of sympathetic activity (Brezenoff, 1973; Buccafusco and Brezenoff, 1979), studies were conducted to investigate the cardiovascular changes evoked in nondependent intact and spinal-transected rats following i.t. administration of cholinergic agonists. This approach was based upon the simplified assumption that since the narcotic withdrawal syndrome is associated with an exaggerated autonomic outflow, central cholinergic hyperactivity could account for this response in dependent rats. In fact, both the direct-acting cholinergic agonist carbachol and the indirect-acting agonist neostigmine elicited marked excitatory cardiovascular changes following i.t. injection. The onset of these responses was almost immediate after carbachol. It is unlikely, therefore, that the cardiovascular responses observed were a result of redistribution of the drug to a more rostral active site. The response to neostigmine, however, was delayed by 3-4 min. This difference was expected, since carbachol can directly activate the cholinergic receptors, while the response to neostigmine would not be expected until a sufficient synaptic increase of $\mathrm{ACh}$ was achieved. This difference in onset of action between the 2 agonists was also observed in earlier experiments in which these drugs wcrc centrally administered (Buccafusco and Breznoff, 1979). The ability of atropine to terminate all of the cardiovascular and behavioral changes associated with i.t. injection of the cholinergic agonists indicates the existence of autonomic spinal muscarinic receptors.

The use of direct- and indirect-acting agonists allowed us to determine whether this cholinergic system originated from supraspinal centers or whether the system was intrinsic to the spinal cord. If the former were true, we would expect that, after C-1 spinal transection, i.t. injection of the direct-acting agonist would continue to evoke a cardiovascular response, equal to or greater (since inhibitory baroreceptor influences would be eliminated) than that in the intact animal. We would have also expected the response to neostigmine to be reduced in spinaltransected animals since the release of $\mathrm{ACh}$ would be all but eliminated. Conversely, if the cholinergic system were intrinsic to the spinal cord, we would expect both agonists to elicit brisk responses. We were therefore surprised to discover that, in fact, both the carbachol and neostigmine responses were markedly reduced in spinal-transected animals.

We interpret these findings as indicating that a cholinergic excitatory pathway descends from supraspinal centers but does not directly innervate the preganglionic sympathetic cell bodies. Instead, this pathway activates muscarinic receptors located upon a noncholinergic, descending sympathoexcitatory pathway that does innervate preganglionic cell bodies. As a result of this synaptic orientation, when the noncholinergic, sympathoexcitatory pathway is severed by spinal transection, cholinergic agonists are no longer capable of augmenting sympathetic outflow. This interpretation is in keeping with our findings that neither i.t. injection of atropine nor of $\mathrm{HC}-3$ influenced resting blood 
pressure or heart rate in any of the experimental paradigms. It therefore appears that a descending cholinergic, spinal facilitatory pathway exists, which when stimulated either directly with carbachol or indirectly with neostigmine mediates an atropine-sensitive, augmented sympathetic outflow. It is of interest to note that a similar descending cholinergic facilitatory pathway mediating the spinal cord flexor reflex has previously been described (Martin and Eades, 1967). At this point it is not possible to determine whether this descending autonomic cholinergic pathway is mono- or polysynaptic, or whether other neurotransmitters are involved.

\section{Evaluation of the effects of intrathecally administered anticholinergic agents on naloxone-precipitated withdrawal}

Several biochemical (Large and Mitton, 1970, 1971; Crossland, 1971, 1973; Domino and Wilson, 1973a, b) and behavioral (Wei et al., 1972; Jhamandas et al., 1973; Pinsky et al., 1973; Bhargava et al., 1974; Frederickson, 1975; Way et al., 1975; Hynes et al., 1976; Vasko and Domino, 1978; Domino, 1979) studies have indicated that $\mathrm{ACh}$ plays a role in narcotic withdrawal. However, the data are conflicting as to whether cholinergic activity is facilitatory or inhibitory to the autonomic and behavioral manifestations of withdrawal. For this reason, further experiments were designed to modify cholinergic transmission in the spinal cords of intact and spinal-transected rats during narcotic withdrawal in an effort to determine the contribution of cholinergic activity to the withdrawal syndrome.

Intrathecal pretreatment with either atropine methyl bromide or $\mathrm{HC}-3$ significantly reduced the magnitude and duration of naloxone-precipitated hypertension (Fig. 3). These findings clearly demonstrate the participation of a spinal cord-mcdiatcd, cholinergic mechanism in the manifestation of withdrawal-associated hypertension. In addition, behavioral signs of withdrawal in these animals were also reduced. The frequency of WBS and the occurrence of DIA were effectively abolished by both pretreatments. In addition, atropine significantly reduced the frequency of ESC (Table 3). These findings present solid evidence for the involvement of cholinergic mechanisms in both the autonomic and certain behavioral components of narcotic withdrawal.

Intrathecal pretreatment of morphine-dependent rats with anticholinergic drugs revealed a very different effect following spinal cord transection. In spinal-transected, dependent rats, i.t. pretreatment with either atropine or $\mathrm{HC}-3$ produced an augmented response to naloxone compared with saline-pretreated rats. The maximal pressor response to naloxone in $\mathrm{HC}-3$ - or atropine-pretreated rats was significantly increased over the control group. It was therefore reasoned that this effect could be accounted for by the existence of an intrinsic spinal inhibitory cholinergic system. In order to substantiate this contention, intact morphine-dependent rats were pretreated with i.t. HC-3 and then withdrawn by an i.t. injection of naloxone. We reasoned that spinal cholinergic neurons would be inhibited by the HC-3 pretreatment and that the subsequent injection of naloxone would produce an augmented pressor response over salinepretreated, morphine-dependent control rats receiving i.t. naloxone. This is, in fact, what occurred. Intrathecal pretreatment with HC-3 significantly augmented the naloxone-induced pressor response over the entire $60 \mathrm{~min}$ withdrawal period (Fig. 5). This finding confirmed, in the intact animal, the presence of an intrinsic spinal, inhibitory cholinergic system. Such a muscarinic inhibitory system, mediating spinal nociceptive processing, has been described in rats (Yaksh et al., 1985). Thus, cholinergic processing of sensory input may be a phenomenon common to several spinal functions.

The role of spinal cholinergic mechanisms in the behavioral response to naloxone was again evident. WBS were abolished by $\mathrm{HC}-3$ pretreatment as well as $\mathrm{CHR}$, which is mediated via the parasympathetic nervous system (Harkness and Ridgway, 1980). It is possible that CHR can be evoked via ascending spinal cholinergic fibers, since this sign was strongly evoked following i.t. naloxone (Table 4).

In summary, at least 2 opposing muscarinic cholinergic mechanisms exist within the rat thoracic spinal cord that are able to exert significant effects upon the cardiovascular system during opiate withdrawal: a descending facilitatory system that augments sympathetic drive and an intrinsic inhibitory system that operates within local cardiovascular reflex circuits to reduce sympathetic outflow. Although autonomic modulation at the spinal cord level most likely involves other neurotransmitter systems, the participation of cholinergic neurons should not be underestimated in cardiovascular regulation.

\section{References}

Bhargava, H. N., S. L. Chan, and E. L. Way (1974) Influence of hemicholinium (HC-3) on morphine analgesia, tolerance, physical dependence and on brain acetylcholine. Eur. J. Pharmacol. 29: 253261 .

Brezenoff, H. E. (1973) Centrally induced pressor responses to intravenous and intraventricular physostigmine evoked via different pathways. Eur. J. Pharmacol. 23: 290-292.

Brezenoff, H. E., and R. Giuliano (1982) Cardiovascular control by cholinergic mechanisms in the central nervous system. Annu. Rev. Pharmacol. Toxicol. 22: 341-381.

Buccafusco, J. J. (1983) Cardiovascular changes during morphine withdrawal in the rat: Effects of clonidine. Pharmacol. Biochem. Behav. 18: 209-215.

Buccafusco, J. J., and R. S. Aronstam (1981) Cholinergic actions of false neurotransmitters: Acetylpyrrolidinecholine. Neurosci. Lett. 23: 319-324.

Buccafusco, J. J., and H. E. Brezenoff (1979) Pharmacological study of a cholinergic mechanism within the rat posterior hypothalamic nucleus which mediates a hypertensive response. Brain Res. 165: 295310.

Buccafusco, J. J., and D. C. Marshall (1985) Dorsal root lesions block the expression of morphine withdrawal elicited from the rat spinal cord. Neurosci. Lett. 59: 319-324.

Bulbring, E., and J. H. Burns (1941) Observations bearing on synaptic transmission by acetylcholine in the spinal cord. J. Physiol. (Lond.) 100: $337-368$.

Crossland, J. (1971) Neurohumoral substances and drug abstinence syndromes. In Advances in Neuropharmacology, O. Vinar, Z. Votava, and P. B. Bradley, eds., pp. 497-523, North-Holland, Amsterdam.

Crossland, J. (1973) Acetylcholine and morphine dependence. In $\mathrm{Ag}$ onist and Antagonist Actions of Narcotic Analgesic Drugs, H. W. Kosterlitz, H. O. J. Collier, and J. E. Villarreal, eds., pp. 232-234, Macmillan, New York.

Delander, G. E., and A. E. Takemori (1983) Spinal antagonism of tolerance and dependence induced by systemically administered morphine. Eur. J. Pharmacol. 94: 35-42.

Domino, E. F. (1979) Opiate interaction with cholinergic neurons. In Advances in Biochemical Psychopharmacology, Vol. 20, Neurochemical Mechanisms of Opiates and Endorphins, H. H. Loh and D. H. Ross, eds., pp. 339-355, Raven, New York.

Domino, E. F., and A. E. Wilson (1973a) Effect of narcotic analgesic agonists and antagonists on rat brain acetylcholine. J. Pharmacol. Exp. Ther. 184: 18-32.

Domino, E. F., and A. E. Wilson (1973b) Enhanced utilization of brain acetylcholine during morphine withdrawal in the rat. Nature 243: 285-286.

Eccles, J. C., P. Fatt, and K. Koketsu (1954) Cholinergic and inhibitory 
synapses in a pathway from motor axon collaterals to motoneurons. J. Physiol. (Lond.) 126: 524-562.

Ficles, J. C., R. M. Eccles, and P. Fatt (1956) Pharmacological investigations on a central synapse operated by acetylcholine. J. Physiol. (Lond.) 131: 154-169.

Fielding, S., J. Wilker, M. Hynes, and H. Lal (1978) A comparison of clonidine with morphine for antinociceptive and antiwithdrawal actions. J. Pharmacol. Exp. Ther. 207: 899-905.

Finberg, J. P. M., J. J. Buccafusco, and S. Spector (1979) Regional brain acetylcholine kinetics: Effects of reserpine. Life Sci. 25: 147156.

Franz, D. N., B. D. Harl, and K. L. McCloskey (1982) Spinal sympathetic neurons. Possible sites of opiate withdrawal suppression by clonidine. Science 215: 1643-1645.

Frederickson, R. C. A. (1975) Morphine withdrawal response and central cholinergic activity. Nature 257: 131-132.

Harkness, J. E., and M. D. Ridgway (1980) Chromodacryorrhea in laboratory rats (Rattus norvegicus): Etiological considerations. Lab. Anim. Sci. 30: 841-844.

Hongo, T., and R. W. Ryall (1966) Electrophysiological and microelectrophoretic studies on sympathetic preganglionic neurons in the spinal cord. Acta Physiol. Scand. 68: 96-104.

Houser, C. R., G. D. Crawford, R. P. Barber, P. M. Salvaterra, and J. E. Vaughn (1983) Organization and morphological characteristics of cholinergic neurons: An immunocytochemical study with a monoclonal antibody to choline acetyltransferase. Brain Res. 266: 97-119.

Hynes, M. D., G. Gianutsos, and H. Lal (1976) Effects of cholinergic agonists and antagonists on morphine-withdrawal syndrome. Psychopharmacology 49: 191-195.

Jhamandas, K., M. Sutak, and S. Bell (1973) Modification of precipitated morphine withdrawal syndrome by drugs affecting cholinergic mechanisms. Eur. J. Pharmacol. 24: 296-350.

Large, W. A., and A. S. Milton (1970) The effect of acute and chronic morphine administration on brain acetylcholine levels in the rat. $\mathrm{Br}$. J. Pharmacol. 38: 451P-452P.

Large, W. A., and A. S. Milton (1971) Effects of morphine, levorphanol, nalorphine and naloxone on the release of acetylcholine from slices of rat cerebral cortex and hippocampus. Br. J. Pharmacol. 41: 398P-399P.

Lebedev, V. P., V. I. Petrov, and V. A. Skobelev (1980) Do sympathetic preganglionic neurons have a recurrent inhibitory mechanism? Pfluegers Arch. 383: 91-97.

Marshall, D. C., and J. J. Buccafusco (1983) Role of central adrenergic and cholinergic neurons in the pressor response associated with morphine withdrawal (abstr.). Proc. Soc. Exp. Biol. Med. 172: 130.

Marshall, D. C., and J. J. Buccafusco (1985a) A comparison of the cardiovascular and the behavioral changes following naloxone as measures of the degree of physical dependence on morphine in rats. Drug Dev. Res. 5: 271-280.

Marshall, D. C., and J. J. Buccafusco (1985b) Supraspinal and spinal mediation of naloxone-induced morphine withdrawal in rats. Brain Res. 329: 131-142.

Marshall, D. C., and J. J. Buccafusco (1985c) Spontaneous morphine withdrawal from the rat spinal cord. Experientia 41: 1151-1152.

Martin, W. R., and C. G. Eades (1964) A comparison between acute and chronic physical dependence in the chronic spinal dog. J. Pharmacol. Exp. Ther. 146: 385-394.

Martin, W. R., and C. G. Eades (1967) Pharmacological studies of spinal cord adrenergic and cholinergic mechanisms and their relation to physical dependence on morphine. Psychopharmacologia 11: 195223.

Martin, W. R., C. G. Eades, J. A. Thompson, R. E. Huppler, and P. E. Gilbert (1976) The effects of morphine and nalorphine like drugs in the nondependent and morphine-dependent chronic spinal dog. J. Pharmacol. Exp. Ther. 197: 517-532.

Merlis, J. K., and H. Lawson (1939) The effect of eserine on spinal reflexes in the dog. J. Neurophysiol. 2: 566-572.

Navarathnam, V., and P. R. Lewis (1970) Cholinesterase containing neurones in the spinal cord of the rat. Brain Res. 18: 411-425.

Pinsky, C., R. C. A. Frederickson, and A. J. Vasquez (1973) Morphine withdrawal syndrome responses to cholinergic antagonists and to a partial cholinergic agonist. Nature 242: 59-60.

Renshaw, B. (1946) Central effects of centripetal impulses in axons of spinal ventral roots. J. Neurophysiol. 9: 191-204.

Schweitzer, A., and S. Wright (1937) The action of eserine and related compounds and of acetylcholine on the central nervous system. J. Physiol. (Lond.) 89: 165-197.

Vasko, M. R., and E. F. Domino (1978) Tolerance development to the biphasic effects of morphine on locomotor activity and brain acetylcholine in the rat. J. Pharmacol. Exp. Ther. 207: 848-858.

Way, E. L., E. T. Iwamoto, N. H. Bhargava, and H. H. Loh (1975) Adaptive cholinergic-dopaminergic responses in morphine dependence. In Advances in Biochemical Psychopharmacology, Vol. 13, Neurobiological Mechanisms of Adaptation and Behavior, A. J. Mandell, ed., pp. 169-184, Raven, New York.

Wei, E., H. H. Loh, and E. L. Way (1972) Neuranatomical correlates of morphine dependence. Science 177: 616-617.

Yaksh, T. L., and T. A. Rudy (1976) Chronic catheterization of the spinal subarachnoid space. Physiol. Behav. 17: 1031-1036.

Yaksh, T. L., R. Dirksen, and G. J. Harty (1985) Antinociceptive effects of intrathecally injected cholinomimetic drugs in the rat and cat. Eur. J. Pharmacol. 117: 81-88. 